\title{
Enumeration of sandy sediment bacteria: search for optimal protocol
}

\author{
Slava S. Epstein ${ }^{*}$, Jeffrey Rossel \\ Marine Science Center, Northeastern University, East Point, Nahant, Massachusetts 01908, USA
}

\begin{abstract}
We examined and compared a variety of existing protocols for enumeration of bacteria from marine sandy sediments. The focus was on how to dislodge bacteria from sediment particles; a commercial blender, an ultrasonic cleaner, and an ultrasonic cell disrupter were tested. The ultrasonic cell disrupter was found to be the most efficient device for bacterial dislodgment. With a $5 \mathrm{~mm}$ microtip vibrating at $109 \mu \mathrm{m}$ amplitude and $20 \mathrm{kHz}$, the optimal sonication time of small $\left(\leq 0.5 \mathrm{~cm}^{3}\right)$ samples was $180 \mathrm{~s}$. Having identified the optimal dislodgment treatment, we went through other steps of sediment bacteria enumeration (use of surfactants, thoroughness of sample washing, bacterial staining and counterstaining, etc.), striving for additional ways of improvement. The result was a protocol that, in our study, gave bacterial counts superior to those obtained by any other protocol currently in use.
\end{abstract}

KEY WORDS: Bacteria · Benthos · Enumeration · Fluorescence $\cdot$ Ultrasonic treatment

\section{INTRODUCTION}

No group of marine organisms has received as much attention as bacteria, and the advances in microbial ecology are indisputable. In view of the obvious progress, it is quite surprising that some fundamental characteristics of field bacterial populations are still difficult to evaluate adequately. One of those characteristics is abundance of bacteria in sediments.

In water-column research, the methodological problems associated with enumeration of bacteria have been solved by progress in membrane technology and the introduction of fluorescent dyes (Zimmerman \& Meyer-Reil 1974, Hobbie et al. 1977, Porter \& Feig 1980). As opposed to water-column bacteria, the majority of benthic bacteria are not suspended in interstitial water but attached to sediment particles. Direct epifluorescence microscopy either does not reveal all the bacteria (muddy sediments; Schallenberg et al. 1989) or is not possible (sandy sediments). Therefore, if benthic bacteria are to be enumerated, they have to be first detached from sediment particles.

\footnotetext{
•E-mail address: sepstein@lynx.dac.neu.edu
}

To date, several approaches have been used for bacterial dislodgment. These are shaking of the sample with water, sediment homogenization in a blender, and sample sonication employing either ultrasonic cleaners (sonic baths) or ultrasonic processors/cell disrupters (sonic probes).

Simple shaking of the sample with water proved to extract only a few percent of the total bacterial assemblage (Dale 1974, Meyer-Reil et al. 1978). The other techniques have all been shown to be relatively effective, but there is disagreement as to which one is the best. Dye (1983) claimed the superiority of homogenization over sonication; Ellery \& Shleyer (1984) found the opposite; Schallenberg et al. (1989) and Velji \& Albright $(1986,1993)$ optimized the protocol employing the ultrasonic processor but did not compare it with the other devices.

The difficulties in the enumeration of sediment bacteria also include uncertainties of what to count as bacteria. Rich in detrital material, benthic samples bring a number of bacteria-sized autofluorescing particles. Further, even highly specific fluorescent dyes such as 4',6-diamidino-2-phenylindol (DAPI) do not work in benthic samples as well as they do for watercolumn samples, a problem that results in quite mis- 
leading non-specific staining. A typical sediment sample thus contains, along with fluorescently stained target bacteria, a number of other similarly sized fluorescing objects.

Resolution of the above difficulties and uncertainties is the subject of the present work. The search for the optimal treatment for bacteria dislodgment was the central point of our work. To maximize bacterial counts, we went through other major steps of sediment bacteria enumeration (use of surfactants, sample washing, counterstaining, etc.). The result was a protocol that, in our study, gave bacterial counts 2 to 8 times higher than other protocols currently in use.

\section{MATERIAL AND METHODS}

Type of the sediment and sampling. Sand samples were collected in March 1992 near the low tidal line of a quiet tidal flat in Massachusetts Bay, near the Marine Science Center of Northeastern University, Nahant, Massachusetts, USA, about $10 \mathrm{~km}$ northeast of Boston. The sand was well sorted with median grain size around $180 \mu \mathrm{m}$. The mass of $1 \mathrm{~cm}^{3}$ of the wet sediment was $1.60 \mathrm{~g}$, which corresponded to $1.21 \mathrm{~g}$ of dry sediment. In the present paper, bacterial density data are expressed as cells $\mathrm{cm}^{-3}$. Multiplication by 0.63 and 0.83 transforms these density data into cells $\mathrm{g}^{-1}$ wet wt and cells $\mathrm{g}^{-1}$ dry wt, respectively.

We collected 50 samples $\left(25 \mathrm{~cm}^{3}\right.$ each) randomly distributed over the tidal flat. Samples were taken by coring the tidal flat sediments to a depth of $4 \mathrm{~cm}$ with $60 \mathrm{ml}$ plastic syringes with the Luer end cut off. Samples were immediately preserved with formaldehyde ( $4 \%$ final concentration), combined, thoroughly mixed, and refrigerated $\left(4^{\circ} \mathrm{C}\right)$ until needed. As a result, we had one large $\left(\sim 750 \mathrm{~cm}^{3}\right)$ source of intertidal sand where the distribution of bacteria was assumed to be homogeneous due to prior thorough mixing.

Sediments for all the following analyses were obtained by subsampling from this sample. Subsampling was done by coring the preserved sample with syringes with the Luer end cut off; in the case of small $\left(<2 \mathrm{~cm}^{3}\right)$ samples, it was difficult to take a subsample of precise volume. These small subsamples were weighed immediately upon coring, and their masses were used to calculate the volumes.

Search for the optimal protocol of sediment bacteria enumeration. Several steps in the protocol for enumeration of benthic bacteria were examined in light of possible optimization or improvement. In sequence, these steps were: (1) sample treatments that precede bacterial dislodgment; (2) dislodgment of bacteria from sediment particles; and (3) staining and counting of bacteria.
(1) Treatments preceding bacterial dislodgment: We examined the effect of Tween 80 and sodium pyrophosphate on the resulting bacterial count. As recommended by Meyer-Reil et al. (1978) and Velji \& Albright $(1986,1993)$, we incubated, prior to any other treatment, triplicate $0.5 \mathrm{~cm}^{3}$ samples for $15 \mathrm{~min}$ with $0.0001 \%$ Tween $80\left(1 \mathrm{mg} \mathrm{l}^{-1}\right)$ or $0.001 \mathrm{M}\left(0.266 \mathrm{~g} \mathrm{l}^{-1}\right)$ sodium pyrophosphate as well as triplicate controls without the surfactants. After the incubation, bacteria were dislodged by sonic probe (180 s treatment) and enumerated as described below.

(2) Dislodgment protocols: We examined 3 different ways to dislodge attached bacteria: homogenization in a blender at $16000 \mathrm{rpm}$ (Waring commercial blender), sonication in a sonic bath (Branson B12 sonifying water bath with $80 \mathrm{~W}$ output), and sonicaton by a sonic probe (Branson cell disintegrator equipped with a $5 \mathrm{~mm}$ $(3 / 16$ inch) tapered microtip, model S-125, $100 \mathrm{~W}$ nominal power output).

Homogenization. Triplicated samples of different volumes $\left(1,2,3\right.$, and $\left.10 \mathrm{~cm}^{3}\right)$ were mixed with 12 to $21 \mathrm{ml}$ of filter-sterilized $(0.2 \mu \mathrm{m}$ pore-size filters) and autoclaved sea water (hereafter called particle-free water). We found it convenient to prepare particle-free water in large quantity and use it for making dilutions as needed. In our experience, the addition of a preservative (we used formaldehyde at $2 \%$ final concentration) was essential to prevent bacterial growth in particle-free water. In addition to these precautions, it was still necessary to check every batch of the particlefree water for the presense of DAPI-stained particles. Batches were refiltered and rechecked if they contained more than $15 \times 10^{3} \mathrm{DAPI}$-stained particles $\mathrm{ml}^{-1}$; considering the volumes of particle-free water used for sample dilution and filter washing, this density would translate into 1 particle per microscopic field under $1250 \times$ magnification.

After mixing with particle-free water, the samples were homogenized in semimicrosized containers ( $250 \mathrm{ml}$ capacity) for $30,60,180$, or $480 \mathrm{~s}$. Upon homogenization, the sample was allowed to stand for $60 \mathrm{~s}$, and the supernatant was carefully pipetted off the sediment. A new portion of particle-free water was added to the sediment to wash out the remaining bacteria. The sample was shaken and allowed to settle for a few seconds before the supernatant was collected. The washing was repeated once more, bringing the total number of washes to 3 . The 3 supernatant fractions were combined together and lightly centrifuged $(500 \times g, 5 \mathrm{~min})$ to settle any bacteria that remained attached to detrital and colloidal particles. Cleared supernatant contained target bacteria, i.e. those dislodged by homogenization.

Sonic bath. Sediment samples $\left(1 \mathrm{~cm}^{3}\right.$, in triplicate) were put into plastic sterile vials ( $5 \mathrm{ml}$ capacity), mixed 
with $1 \mathrm{ml}$ of particle-free water, and sonicated for 3,10 , 30 , or $90 \mathrm{~min}$. Starting from the $10 \mathrm{~min}$ sonication, it was necessary to fill the bath with ice water (and, in the case of the $90 \mathrm{~min}$ treatment, periodically replace it) to prevent sample overheating. Although ice melted within a few minutes of continuing sonication, the samples stayed cool (under $20^{\circ} \mathrm{C}$ ) for $15 \mathrm{~min}$, so that even in the longest treatment $(90 \mathrm{~min})$ the ice had to be added only a few times. The sediment was washed, and the supernatant fractions were combined and centrifuged as described above.

Sonic probe. Triplicate sediment samples $(0.05,0.5,2$, or $10 \mathrm{~cm}^{3}$ in volume) were put into plastic sterile vials (50 ml capacity) and mixed with $5 \mathrm{ml}$ of particle-free water. The $20 \mathrm{kHz}$ sonic probe was then inserted into the sediment, and samples were sonicated (109 $\mu \mathrm{m}$ amplitude; setting 4 of the output control) for $3,30,45,60$, 90,180 , or $360 \mathrm{~s}$. Several additional samples $\left(0.5 \mathrm{~cm}^{3}\right.$ in volume, 30,90 , and $120 \mathrm{~s}$ sonication time) were treated with approximately 250 to $300 \mu \mathrm{m}$ amplitude (setting 7).

To prevent overheating, each sonication was interrupted twice, with each treatment thus divided into 3 equal periods of sonication with at least $30 \mathrm{~s}$ between them. The treatments therefore were $3 \times 1,3 \times 10$, $3 \times 15, \ldots, 3 \times 120 \mathrm{~s}$. In cases of prolonged sonication (more than $30 \mathrm{~s}$ total), it was necessary to put vials with samples on ice during sonication to keep the sample temperature under $20^{\circ} \mathrm{C}$.

After sonication, the sediment was vigorously shaken by hand and allowed to settle for $5 \mathrm{~s}$ before the supernatant was collected. Washing was repeated 2 more times, each time with $5 \mathrm{ml}$ of particle-free water. The 3 supernatant fractions were combined and centrifuged as above to leave in suspension only detached bacteria. When total (dislodged plus still attached to detritus) bacterial counts were needed, supernatants were not centrifuged. In these trials, i.e. trials requiring total bacterial counts, we also varied the number of washes from 3 to 18 to find the washing protocol optimal for removal of bacteria from the sediment.

Evaluation of potential damaging impact of sonication on bacteria. We checked if sonication would destroy bacteria suspended in water. Free bacteria were obtained by sediment homogenization (see above), stained with DAPI and enumerated as described below. A known number of cells was sonicated for $180 \mathrm{~s}$, and the density was checked again. The experiment was run in triplicate.

(3) Staining and counting: Supernatants resulting from dislodgment treatments were appropriately subsampled, and subsamples were stained with either DAPI or Acridine Orange (AO).

DAPI staining. We used the protocol of Porter \& Feig (1980) as modified by Schallenberg et al. (1989) who suggested increasing the stain concentration up to $5 \mu \mathrm{g}$ $\mathrm{ml}^{-1}$ final concentration. After $15 \mathrm{~min}$ staining, bacteria were concentrated onto Poretics polycarbonate black filters $(0.2 \mu \mathrm{m}$ pore size $)$ and rinsed twice for $5 \mathrm{~min}$ with particle-free water.

In several trials, we used Evans Blue as a DAPI counterstain (Autio \& Mattila-Sandholm 1992). The counterstain was added $\left(10^{-1}, 10^{-2}, 10^{-3}, 10^{-4}, 10^{-5}, 10^{-6}\right.$, or $10^{-7} \%$ final concentration) to samples simultaneously with DAPI.

AO staining. We followed the protocol of Hobbie et al. (1977) (0.01\% final dye concentration for $5 \mathrm{~min})$ with 1 modification: a surfactant was not used to wet the filters as Poretics filters were sufficiently hydrophilic. After staining, bacteria were concentrated on the filter and washed as above.

Counting. Filters with bacteria stained with either dye were examined under a Leitz Dialux 20 microscope equipped for epifluorescence (DAPI-filter set included 340 to $380 \mathrm{~nm}$ excitation filter, $400 \mathrm{~nm}$ beam splitter, and $430 \mathrm{~nm}$ barrier filter; AO-filter set included 390 to $490 \mathrm{~nm}$ excitation filter, $510 \mathrm{~nm}$ beam splitter, and $515 \mathrm{~nm}$ barrier filter). On each filter, no fewer than 200 cells were counted in at least 15 microscopic fields.

SEM observations. To verify counts obtained with DAPI staining, 2 samples were examined under an Amray AMR-1000 SEM. The two $0.5 \mathrm{~cm}^{3}$ samples were preserved with glutaraldehyde $(2 \%$ final concentration), sonicated for $180 \mathrm{~s}$, and washed 3 times. Supernatants with extracted bacteria were subsampled, subsamples concentrated on $0.2 \mu \mathrm{m}$ pore-size Poretics polycarbonate filters, rinsed several times with particle-free water, dehydrated in a series of ethanol solutions $(30,50,70,96,100,100,100 \%)$, and were passed through a critical point dryer (Samdri 790, Tousimis Research Co.). Appropriate pieces of membranes were mounted on SEM stubs with double stick tape, sputter coated with $40 \%$ gold $/ 60 \%$ palladium (10 $\mathrm{nm}$ thick layer), and were examined under SEM with $20 \mathrm{kV}$ accelerating regime. Photographs were made on Polaroid Type 55 film.

Masking effect. We checked if detrital particles could mask some of the bacteria, as this might decrease bacterial counts or in some way change the appearance of fluorescently stained bacteria. Klebsiella pneumoniae ATCC 27889 grown on Marine Broth (Difco) were preserved in formaldehyde ( $2 \%$ final concentration), stained with DAPI and cleansed of the stain by repetitive centrifugation $(13600 \times g, 5 \mathrm{~min})$ followed by resuspension in particle-free water ( 3 cycles). The suspension was filtered through $3.0 \mu \mathrm{m}$ pore-size Poretics filters to remove clumps. DAPI-stained cells were enumerated, mixed with detrital particles, and re-enumerated in the presence of detritus. Detrital particles were obtained in the following way: a $0.5 \mathrm{~cm}^{3}$ sediment sample was sonicated (180 s), washed 3 times, and supernatants 
with detritus washed from the sand were combined. Thus, DAPI-stained bacterial tracers were mixed with detrital particles typically present in the actual bacterial enumeration trials.

Statistical analyses. To assess significance of the differences between bacterial counts obtained by different enumeration protocols, the $t$-test was employed throughout the study. Its use was justified as (1) the density data were normally distributed [checked by a standard graphical test (Sokal \& Rohlf 1987, p. 85-92)], and (2) the test for homogeneity of variances $\left(F_{\max }\right.$ test; Sokal \& Rohlf 1987, p. 213) showed that our samples were homoscedastic. The normal distribution of bacterial abundance data and homogeneity of variances should be expected since all the samples were drawn from a single, carefully mixed large source of the sediment.

\section{RESULTS}

\section{General observation}

DAPI-stained sediment samples invariably contained differently stained bacteria-sized objects. There were 2 relatively well defined classes of these objects. The first class was represented by cocci and rods fluorescing bright blue; in the present study, these were always considered to be bacteria. The second class was represented by particles fluorescing yellow; they are hereafter called UYOs (Unidentified Yellow Objects). The fluorescence intensity was different among UYOs, and ranged from easily distinguishable bright yellow to almost indiscernible from background. The size of UYOs varied widely too, from objects that were several microns in size to very small dots at the limit of the microscope resolution power. Many UYOs were of irregular shape, others appeared to be rods or cocci, still others were too small to determine their shape. Given the range of these variations, a substantial number of UYOs naturally fell into typically bacterial size- and shape-classes. This resulted in an uncertainty in what to count as bacteria, and this uncertainty had to be resolved prior to actual counting.

UYOs were invariably associated with detrital particles; they numbered from several to tens per typical 10 to $20 \mu \mathrm{m}$ sized particle. It was difficult to get a better estimate of UYO density per particle as many UYOs were fluorescing so weakly that counts would not be reliable and reproducible. On the particle surface, in addition to UYOs, there was, of course, a certain number of fluorescing blue bacteria; these numbered 0 to 3 per particle. In order to decide whether at least some UYOs were indeed bacteria on the surface of detrital particles, we examined these particles under SEM.
SEM images did not reveal bacteria on the surface of the detrital particles in quantities corresponding to the expected UYO number (Fig. 1). Occasionally, there were typical bacteria attached to particles (Fig. 1), but these were few, from 0 to 2 on the upper particle surface. That corresponded well to the number of fluorescing blue bacteria ( 0 to 3 entire particle). We concluded that UYOs were not bacteria, nor were they dead/damaged cells/capsules, associated with detrital particle surface.

A possibility, however, remained that UYOs were in fact bacteria, though not on the surface of the particle (and thus observable by SEM) but rather embedded in its matrix. Our hypothesis was that the properties of that matrix were such that otherwise blue cells would appear yellow once embedded in or covered by a particle. We checked this possibility by studying the masking effect of detritus, i.e. by mixing DAPI-prestained bacteria with detrital particles derived from the sediment. The blue cells were enumerated before and after addition of detritus; the counts were $1.00 \pm 0.09(\mathrm{SE}) \times 10^{9}$ and $1.08 \pm$ $0.24 \times 10^{9}$ cells cm ${ }^{-3}$, respectively. There was no statistically significant difference between these counts at the $\alpha=0.05$ level. Bacteria were all uniformly blue regardless of whether they were positioned on, under, or apart from detrital particles.

On the basis of direct SEM observation and checking for masking effect, we came to a tentative conclusion that only fluorescing blue objects of appropriate size were to be counted as bacteria. We proceeded then with the evaluation of bacteria dislodgment protocols.

\section{Search for the optimal protocol of sediment bacteria enumeration}

Treatments preceding bacterial dislodgment

We tested for positive effects of surfactants on the efficacy of the following dislodgment. The results are shown in Fig. 2. Sample pre-incubation with sodium pyrophosphate appeared to increase, and that with Tween 80 to decrease, the bacterial count in comparison to control (no pre-incubation); neither difference was statistically significant at the $\alpha=0.05$ level.

\section{Dislodgment of bacteria from sediment particles}

Homogenization. Results of a typical experiment are shown in Fig. 3. The highest bacterial numbers were observed in the shortest ( $30 \mathrm{~s})$ treatments. The number of bacteria put into suspension declined almost 2 -fold as homogenization time increased to $60 \mathrm{~s}$, and 7 -fold with further increase to $8 \mathrm{~min}$. 


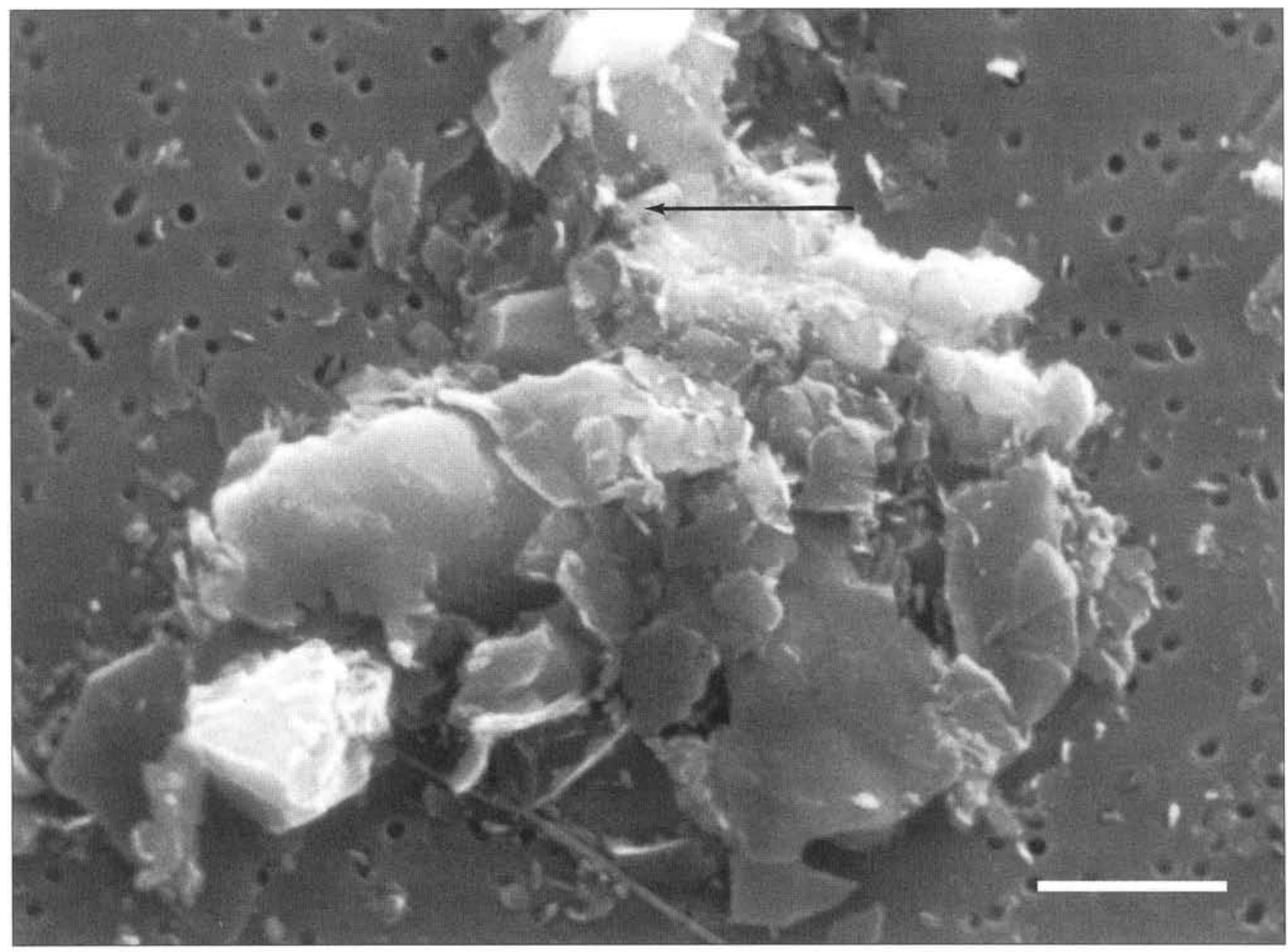

Fig. 1. A typical SEM image of detrital particles from the sediment. The detrital particles appear to be largely free of bacteria; a probable bacterium is indicated by an arrow. Under an epifluorescence microscope, tens of 'unidentified yellow objects' would have been found associated with the particles. Scale bar $=2 \mu \mathrm{m}$

There was no clear effect of sample size on resultant bacterial counts.

The highest bacterial count ever observed in sandy sediment homogenization treatments was $3.76 \pm 0.12$ (SE) $\times 10^{8}$ cells $\mathrm{cm}^{-3}\left(30 \mathrm{~s}\right.$ homogenization, $10 \mathrm{~cm}^{3}$ samples).

Sonic bath. The results of the sonic bath experiments are shown in Fig. 3. The shortest (1 to $3 \mathrm{~min}$ ) treatments resulted in poor bacterial counts. As the sonication time increased from 3 to $10 \mathrm{~min}$, the resultant bacterial counts increased approximately 2-fold. Further increase in sonication time up to 90 min made bacterial counts drop approximately $15 \%$; the drop was not statistically significant at the $\alpha=0.05$ level.

Maximal figures for bacterial density obtained in sonic bath treatments were similar to those in homogenization treatments, with the highest bacterial density registered being $3.12 \pm 0.63(\mathrm{SE}) \times 10^{8}$ cells $\mathrm{cm}^{-3}$ (10 min sonication, $1 \mathrm{~cm}^{3}$ samples).
Sonic probe. The main results of the sonic probe experiments are shown in Fig. 4. The length of sonica-

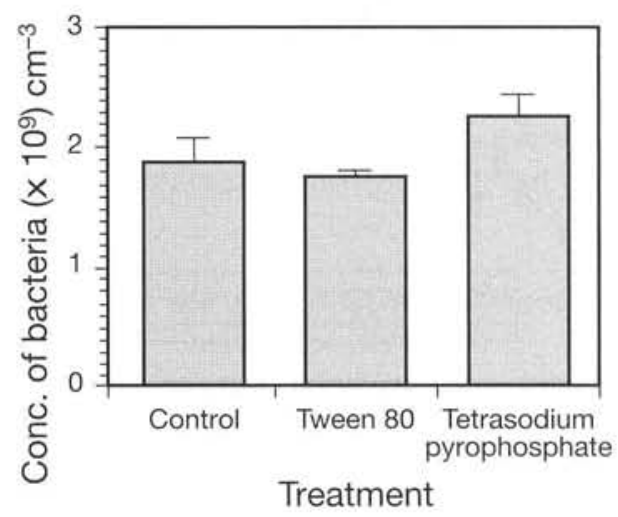

Fig. 2. Effect of Tween 80 and tetrasodium pyrophosphate on enumeration of sediment bacteria. Standard error is shown 


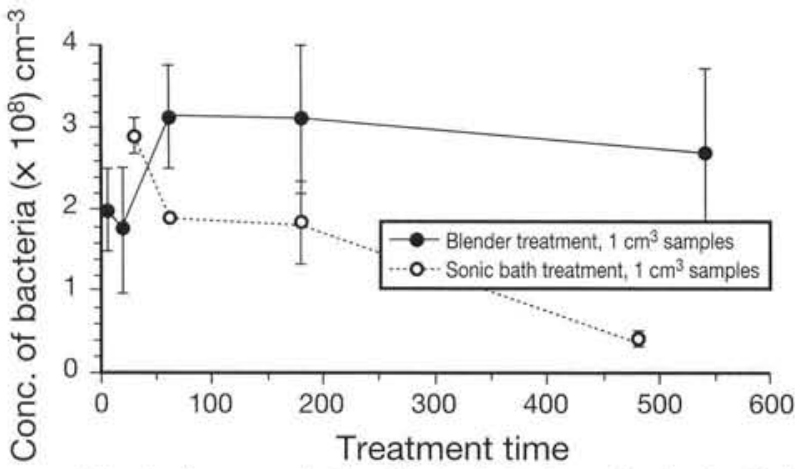

Blender homogenization (s); Sonic bath sonication ( $x 10 \mathrm{~s}$ )

Fig. 3. Effect of homogenization and sonic bath treatment on the number of bacteria dislodged from sediment particles. Standard error is shown

tion considerably influenced the outcome of bacterial enumeration, with the overall pattern somewhat similar to that obtained in sonic bath treatments. In experiments employing $0.5 \mathrm{~cm}^{3}$ samples, the shortest, $3 \mathrm{~s}$ long, sonication resulted in the lowest count. With progressively increased duration of sonication, the bacterial counts first increased steeply reaching the maximum $\left[1.27 \pm 0.16(\mathrm{SE}) \times 10^{9}\right.$ cells $\left.\mathrm{cm}^{-3}\right]$ at $180 \mathrm{~s}$ sonication, and then dropped approximately 3 -fold at longer, $360 \mathrm{~s}$ sonication (the drop was statistically significant at the $\alpha=0.001$ level). The pattern was essentially the same in other sample sizes, although the maximum bacterial count in $2 \mathrm{~cm}^{3}$ sample-size treatments was reached at shorter, $45 \mathrm{~s}$ long, sonication (data not shown).

We also examined the effect of sample size on the result of sonication. Fig. 5 shows that, under optimal sonication conditions $\left(180 \mathrm{~s}\right.$ for $0.05,0.5$, and $10 \mathrm{~cm}^{3}$ samples; $45 \mathrm{~s}$ for $2 \mathrm{~cm}^{3}$ samples), bacterial counts were the highest in the smallest sample-size classes. As the

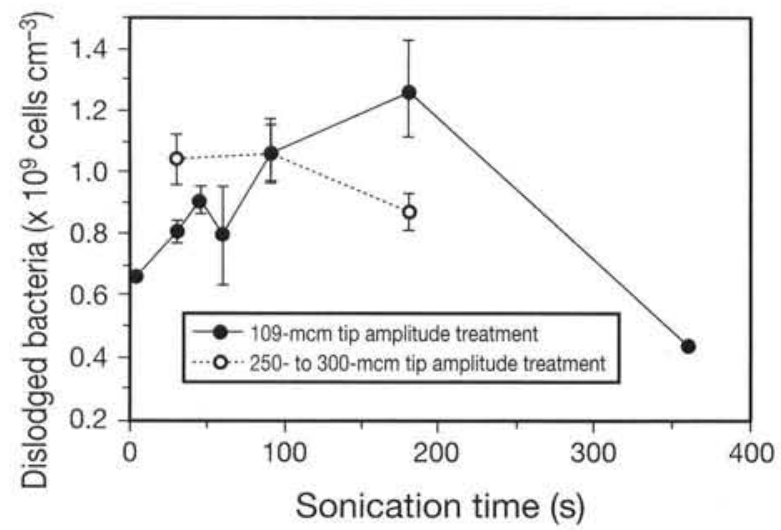

Fig. 4. Effect of ultrasound treatment by the sonic probe on the number of bacteria dislodged from sediment particles. Standard error is shown

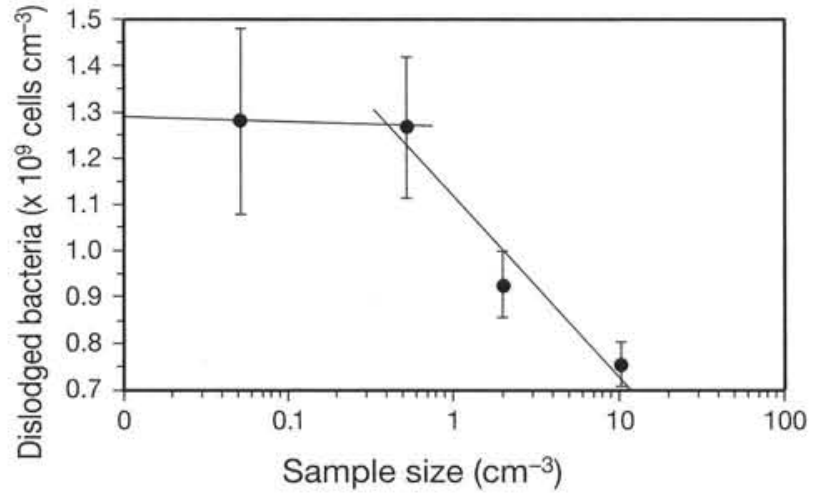

Fig. 5. Effect of sediment sample size on the efficacy of ultrasound treatment by the sonic probe. The experimental data are approximated by 2 linear regressions. Standard error is shown

sample size increased 200-fold (from 0.05 to $10 \mathrm{~cm}^{3}$ ), the bacterial counts decreased on average by $70 \%$.

Bacterial counts obtained with $180 \mathrm{~s}$ sonication of 0.05 and $0.5 \mathrm{~cm}^{3}$ sand samples (experiments were run in over 20 relicates) were thus $238 \%$ higher than the highest figure from the blender homogenization treatment, $307 \%$ higher than that from the sonic bath treatment, and 20 to $185 \%$ higher than that from any other sonic probe treatment.

We checked for a positive effect of increased sonic probe power output (higher microtip amplitude; see 'Treatments preceding bacterial dislodgement' below for more details concerning the principles of ultrasonic action). All the above experiments were performed at $109 \mu \mathrm{m}$ probe tip amplitude, and we tested this regime against a higher setting ( 250 to $300 \mu \mathrm{m}$ amplitude). The results (Fig. 4) showed that there was a small but statistically significant $(\alpha=0.01)$ difference between these protocols with the former giving superior bacterial counts.

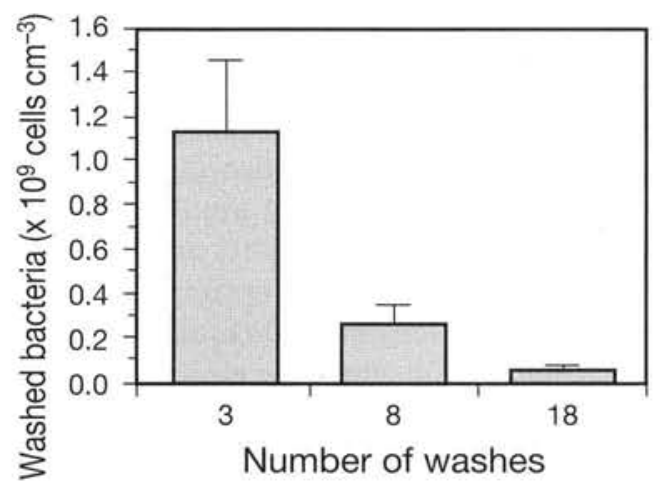

Fig. 6. Effect of post-sonication sample washes on the number of bacteria extracted from the sediment. Standard error is shown 
We examined the effect of an increased number of post-sonication washes on the number of extracted bacteria (Fig. 6). The cumulative bacterial counts grew as the number of washes increased to 18 , but there was no statistically significant effect at the $\alpha=0.05$ level after more than 8 washes.

Evaluation of potential damaging impact of sonication on bacteria. No statistically significant destruction of formaldehyde-fixed bacteria in suspension resulted from the $180 \mathrm{~s}$ long sonication. The densities of the DAPI-stained bacteria before and after sonication were almost identical $\left[3.48 \pm 0.43(\mathrm{SE}) \times 10^{7}\right.$ and $3.44 \pm$ $0.0 .71 \times 10^{7}$ cells $\mathrm{ml}^{-1}$, respectively].

\section{Staining and counting}

We examined the effect of counterstaining DAPI with Evans Blue on the number of counted bacteria, UYOs, and general quality of the image. The data are summarized in Fig. 7. High concentrations of the counterstain $\left(>10^{-3} \%\right)$ made images very $\operatorname{dim}$, and the counts were inferior. As the counterstain concentration decreased to $10^{-6} \%$, the bacterial count increased and exceeded the control by $26 \%$; the increase was not statistically significant at $\alpha=0.05$, but was significant at the $\alpha=0.10$ level. Further decrease in the counterstain concentration coincided with a decrease in bacterial count to the level of the control. Though the statistical significance of the positive effect of counterstaining on bacterial counts was doubtful at either counterstain concentration, there was a noticeable qualitative improvement: $10^{-5}$ to $10^{-7} \%$ concentrations of Evans Blue resulted in superior bacterial images, reduced background, increased contrast, and decreased number of confusing UYOs.

We compared DAPI counts $\left[1.85 \pm 0.23(\mathrm{SE}) \times 10^{9}\right.$ cells $\mathrm{cm}^{-3}$; Fig. 7] with those obtained with widely used $\mathrm{AO}$. The latter was somewhat lower [1.55 \pm 0.51 (SE) $\times 10^{9}$ cells cm$~_{-3}$ ] but the difference was not statistically significant $(\alpha=0.05)$. There were, however, qualita-

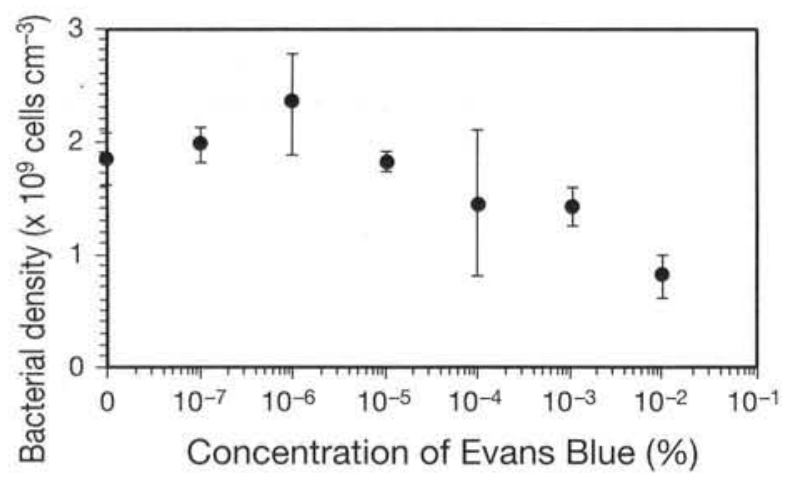

Fig. 7. Effect of counterstaining (Evans Blue) on the number of enumerated bacteria. Standard error is shown tive differences between the 2 stains. On AO-stained slides, no confusing objects comparable to UYOs in DAPI-stained samples were noticed, yet the background fluorescence of AO-stained filters was fairly high, and overall bacterial image quality was inferior compared to DAPI-stained slides.

\section{DISCUSSION}

The main goal of the present work was to find the optimal protocol(s) for enumeration of bacteria in marine sandy sediments. In the introductory remarks, we argued that the 2 main problems associated with quantification of benthic bacteria were (1) uncertainties as to what to consider bacteria (at least in DAPIstained samples) and (2) how to effectively dislodge and separate bacteria from sediment particles.

\section{Identification of bacteria for enumeration}

We attempted to resolve the uncertainties in question by comparing a typical DAPI-stained sample with its SEM image, and by studying sediment masking effect. SEM photographs (Fig. 1) showed that the bacteriasized yellow-colored objects abound on DAPI-stained slides were neither intact nor damaged/empty bacteria on detrital particle surface. A possibility remained that UYOs were DAPI-stained bacteria embedded into particle matrix - provided the matrix blocked or changed the UV excitation or cell fluorescence in such a way that otherwise blue cells appeared yellow. We checked this hypothesis by mixing DAPI-prestained bacteria with non-stained detrital particles. The idea was to see if those blue bacteria positioned under the particles would appear yellow. All DAPI-prestained bacteria were recovered, all fluoresced blue, no UYOs were found, and we came to the conclusion that UYOs were artifacts of DAPI-staining and thus not to be counted as bacteria. This conclusion was later confirmed in another, non-related study, where we examined DAPI-stained detrital particles formed in axenic algae culture. Being axenic, the culture medium did not contain any bacteria, yet detrital particles were universally associated with UYOs.

\section{Search for the optimal protocol of sediment bacteria enumeration}

Treatments preceding bacterial dislodgment

Several studies (Meyer-Reil et al. 1978, Velji \& Albright 1986, 1993, Alongi 1988) suggested that sequestering agents, deflocculents, and surfactants 
such as sodium pyrophosphate or Tween 80 added to the sample might be beneficial for bacteria enumeration. In our study, sample incubation in these agents did not statistically increase the number of bacteria but they were more evenly distributed on the filter (also noted by Velji \& Albright 1986).

\section{Dislodgment of bacteria from sediment particles}

The necessity of dislodgment prior to enumeration has been repeatedly shown in the past (Zvyagintsev \& Galkina 1967, Dale 1974, Meyer-Reil et al. 1978, Dye 1983, Ellery \& Schleyer 1984, Velji \& Albright 1986 , 1993). The dislodgment could be achieved by homogenization in a blender, sonication in a sonic bath, or by sonication with a sonic probe. In our experiments, the efficacy of the first 2 devices was similar. This finding corresponds well to the earlier study of Ellery \& Schleyer (1984) who found that their use resulted in essentially the same bacterial counts. The sonic probe was by far more superior; for similarly sized samples, the use of this device (180 s regime, Fig. 4; also Starink et al. 1994) always resulted in bacterial counts severalfold higher than attained by either of the other 2 devices. Earlier (Dye 1983), the opposite was shown. We believe that the main reason for this discrepancy was the difference in the employed protocols. Dye (1983) used a very mild sonication regime ( $8 \mu \mathrm{m}$ amplitude vs $109 \mu \mathrm{m}$ in the present work) which might result in inefficient bacterial dislodgment.

The use of the sonic probe might result in destruction of some cells. To quantify this possible negative effect, we added a known number of DAPI-stained bacteria to particle-free water. The $180 \mathrm{~s}$ sonication of the mixture revealed no drop in the number of DAPI-stained tracers. This indicated, at least for the integrity of formaldehyde-fixed bacteria in suspension, an apparent harmlessness of the chosen sonication regime.

Therefore, an ultrasonic processor appears to be the device of choice. This brings a very important question: how is it possible to reproduce a protocol employing a sonic probe? In order to answer this question a short excursion into the principles of sonication treatment is needed; more details can be found in Frederick (1965).

Ultrasonic processors convert electrical current into $20 \mathrm{kHz}$ mechanical vibration of a horn-like probe. A microtip attached to the horn amplifies these vibrations. As a result, pressure waves are created in the sample that cause particles to disintegrate, bacteria to dislodge, etc. The design of this device is such that the tip will maintain the amplitude of its vibration against whatever resistance it receives from the sample. It works in a fashion similar to cruise-control in automo- biles: just as different amounts of engine power are required to maintain a preset speed downhill as opposed to uphill, different samples draw from the sonic probe different amounts of energy. Therefore, the ultrasonic processor will deliver to the sample as much power as needed to maintain the amplitude preset by a 'power output' or 'amplitude control' switch. This will be so as long as the power level, dictated by the nature of the sample, is below the nominal power of the unit. Usually, sediment samples require under $50 \mathrm{~W}$ ( $5 \mathrm{~mm}$ tips) and under $25 \mathrm{~W}$ ( $3 \mathrm{~mm}$ tips) for most of the amplitude settings. Thus, there is no difference between sonic treatment of a given sample by a 50 , 100 , or $200 \mathrm{~W}$ nominal power unit provided the units are equipped with similar microtips set to the same amplitude. Conversely, similar units would provide drastically different treatment if their settings or tips were different.

Amplitude of the tip vibration emerges as the single most important characteristic of a protocol; the nominal power of an ultrasonic processor is of secondary importance. Unfortunately, it is exactly the latter, not the former, that researchers typically give in papers [the only exception of which we are aware is the paper by Dye (1983)]. This makes it difficult to reproduce the published protocols.

The second important parameter to consider is the geometry of the probe. The power being delivered to the sample is highly concentrated around the tip of the probe; this makes sonication by sonic probe drastically different from that in a sonic bath. Ultrasonic processors provide output intensities from several hundred to several thousand $\mathrm{W} \mathrm{cm}^{-2}$, whereas sonic bath output intensity is around $1 \mathrm{~W} \mathrm{~cm}^{-2}$. This may explain why sonic bath treatments, no matter how long they were, did not result in bacterial counts comparable to those from sonic probe treatments.

The importance of the size and shape of the microtip for the effect of sonication has an important consequence. A small tip may be able to provide equal treatment throughout the sample only if the sample is correspondingly small, and may not be able to agitate samples of larger size optimally in all their parts. In other words, bacterial counts obtained with a single microtip may be sample-size dependent. This is well illustrated by the present results: sonication of samples 0.05 to $0.5 \mathrm{~cm}^{3}$ in volume resulted in similar bacterial counts, but as the sample size increased to 2 and $10 \mathrm{~cm}^{3}$, bacterial counts $\mathrm{cm}^{-3}$ decreased by 37 and $68 \%$, respectively (Fig. 5). Therefore, relatively large samples $\left(>2 \mathrm{~cm}^{3}\right.$ ) will require a larger microtip and thus another series of scaling experiments.

In conclusion, the ultrasonic processor/sonic probe appeared to be the most effective device for bacterial dislodgment. In our experiments, the optimal protocol 
was as follows: sample size $<0.5 \mathrm{~cm}^{3}$, the length of the treatment $3 \times 60 \mathrm{~s}$, the microtip size $5 \mathrm{~mm}$, and the amplitude of microtip vibrations $109 \mu \mathrm{m}$. The number of post-treatment washes necessary to extract essentially all the bacteria was 8 (Fig. 6). We are aware of only 1 study where a similar dislodgment protocol was used $(2.5 \mathrm{~min}$ sonication by a sonic probe with $100 \mathrm{~W}$ nominal power; Starink et al. 1994).

All the above parameters of sonication regime are essential to reproduce the dislodgment protocol. If a different unit is to be used, then charts that show what 'power output' or 'amplitude control' setting corresponds to what amplitude with what type of microtip may be needed; these charts are sometimes available only from the manufacturer.

\section{Staining and counting}

We tried to improve the performance in the fluorescent staining of bacteria. The main goal was to eliminate a high degree of subjectivity involved in counting fluorescently stained bacteria. This could be acheived by reducing the background fluorescence and nonspecific staining and/or by making bacterial images brighter. We did not find the use of $\mathrm{AO}$ as a solution: though UYOs, i.e. fluorescing yellow bacteria-sized objects of undetermined nature) disappeared, background fluorescence was high, image contrast low, and the process of counting AO-stained bacteria effortconsuming and somewhat subjective. This may not be applicable to water-column samples; a recent study (Suzuki et al. 1993) showed the superiority of AO over DAPI for staining planktonic bacteria.

The use of Evans Blue as a counterstain, suggested by its similar use in food microbiology (Autio \& MattilaSandholm 1992), appeared to have some benefits. In some concentrations $\left(10^{-5}\right.$ to $10^{-7}$, especially $\left.10^{-6} \%\right)$, this counterstain increased the contrast between background and DAPI-stained cells, helped to resolve closely spaced bacteria, and reduced the level of non-specific staining.

On the basis of the described experiments, we suggest a protocol for enumeration of bacteria from sandy sediments. The proposed protocol results in (1) maximization of the number of dislodged sediment bacteria, (2) separation of freed bacteria from the majority of obscuring sediment particles, and (3) enhanced images of bacteria under epifluorescence illumination. The full protocol consists of the following steps:

(1) Sampling. If a $5 \mathrm{~mm}$ microtip is to be used for sonication, samples should be $\leq 0.5 \mathrm{~cm}^{3}$ in volume.

(2) Preservation in formaldehyde, $4 \%$ final concentration.

(3) Dilution (in the present work 1:10); this may be combined with $15 \mathrm{~min}$ incubation in surfactants such as sodium pyrophosphate and/or Tween 80 (Velji \& Albright 1993) as a dislodging aid.

(4) Sonic treatment. Sample is sonicated for $180 \mathrm{~s}$ by a sonic probe equipped with $5 \mathrm{~mm}$ microtip at $109 \mu \mathrm{m}$ amplitude. To prevent sample heating, (a) the treatment is divided into three $60 \mathrm{~s}$ long intervals with 1 to 2 min cooling periods between them, and (b) samples are kept on ice during sonication.

(5) Washing. $5 \mathrm{ml}$ of filter-sterilized and autoclaved sea water is added to the sediment, the mixture is vigorously shaken, the sediment particles are allowed to settle down, and supernatant is collected. The procedure is repeated 8 times with all the supernatants combined and thoroughly mixed.

(6) Counting. After the resultant mixture is appropriately subsampled, bacteria are stained for 10 to 15 min with DAPI [ $5 \mu \mathrm{g} \mathrm{ml}^{-1}$ final concentration; Schallenberg et al. (1989)]. Simultaneously with DAPI, a solution of Evans Blue $\left(10^{-5}\right.$ to $10^{-7} \%$ final concentrations) may added to the sample as a counterstain to reduce background and enhance bacterial images.

(7) Upon staining, bacteria are concentrated on 0.2 $\mu \mathrm{m}$ pore size polycarbonate membrane filter, rinsed, and counted under epifluorescent illumination (Hobbie et al. 1977, Porter \& Feig 1980).

Acknowledgements. We thank Bill Fowle for help in SEM observations. We are indebted to $\mathrm{Mr}$ Michael Donaty from Sonic \& Materials, Inc., Danbury, CT, for his consultations on the principles of ultrasonic treatment and design of ultrasonic processors; the analogy between the work of a sonic probe and cruise-control in automobiles was suggested by him. Many thanks to Michael Claes for his help and encouragement at various moments throughout the study. We appreciate the valuable comments of Dr. Frank Gibbard which clarified and simplified the manuscript. A very extensive, thorough, and detailed review by 1 anonymous reviewer significantly improved the manuscript. This work was financially supported by NSF Grant OCE-9217250 to S.S.E. This is contribution no. 207 of Marine Science Center of the Northeastern University, Nahant, MA, USA.

\section{LITERATURE CITED}

Alongi, D. M. (1988). Bacterial productivity and microbial biomass in tropical mangrove sediments. Microb. Ecol. 15: $59-79$

Autio, K., Mattila-Sandholm, T. (1992), Detection of active yeast cells (Saccharomyces cerevisiae) in frozen dough sections. Appl. environ. Microbiol. 58: 2153-2157

Dale, N. G. (1974). Bacteria in intertidal sediments: factors related to their distribution. Limnol. Oceanogr. 19: 509-518

Dye, A. H. (1983). A method for the quantitative estimation of bacteria from mangrove sediments. Estuar. coast. Shelf Sci. 17: 207-212

Ellery, W. N., Schleyer, M. H. (1984). Comparison of homogenization and ultrasonication as techniques in extracting attached sedimentary bacteria. Mar. Ecol. Prog. Ser. 15: $247-250$

Frederick, J, R. (1965). Ultrasonic engineering. John Wiley \& Sons, New York 
Hobbie, J. E., Daley, R. J., Jasper, S. (1977). Use of Nuclepore filters for counting bacteria by fluorescence microscopy. Appl. environ. Microbiol. 33: 1225-1228

Meyer-Reil, L. A., Dawson, R., Liebezeit, G., Tiedge, H. (1978). Fluctuations and interactions of bacterial activity in sandy beach sediments and overlying waters. Mar. Biol. 48: $161-171$

Porter, K. G., Feig, Y. C. (1980). The use of DAPI for identifying and counting aquatic microflora. Limnol. Oceanogr. 25: $943-948$

Schallenberg, M., Kalff, J., Rasmussen, J. B. (1989). Solutions to problems in enumerating sediment bacteria by direct counts. Appl. environ. Microbiol. 55: 1214-1219

Sokal, R. R., Rohlf, F. J. (1987). Introduction to biostatistics, 2nd edn. W. H. Freeman, San Francisco

Starink, M., Krylova, I. N., Bär-Gilissen, M. J., Bak, R. P. M., Cappenberg, T. E. (1994). Rates of benthic protozoan grazing on free and attached sediment bacteria measured with fluorescently stained sediment. Appl, environ. Microbiol. 60: $2259-2264$

This article was submitted to the editor
Suzuki, M. T., Sherr, E. B., Sherr, B. F. (1994). DAPI direct counting underestimates bacterial abundances and average cell size compared to AO direct counting. Limnol. Oceanogr. 38: 1566-1570

Velji, M. I., Albright, L. J. (1986). Microscopic enumeration of attached marine bacteria of seawater, marine sediment, fecal matter, and kelp blade samples following pyrophosphate and ultrasound treatments. Can. J. Microbiol. 32: 121-126

Velji, M. I., Albright, L. J. (1993). Improved sample preparation for enumeration of aggregated aquatic substrate bacteria. In: Kemp, P. F., Sherr, B. F., Sherr, E. B., Cole, J. J. (eds.) Aquatic microbial ecology. Lewis Publ., Boca Raton, p. 139-142

Zimmerman, R., Meyer-Reil, L.-A. (1974). A new method for fluorescence staining of bacterial populations on membrane filters. Kiel. Meeresforsch. 30: 24-27

Zvyagintsev, D. C., Galkina, G. M. (1967). Ultrasonic pretreatment of soil for microbiological assay. Mikrobiologiya 36: 1087-1095

Manuscript first received: June 17, 1994

Revised version accepted: September 28, 1994 